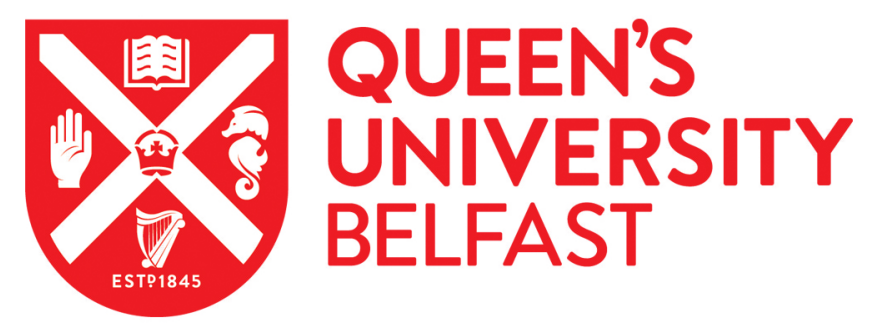

\title{
Numbered-up gas-liquid micro/milli channels reactor with modular flow distributor
}

Al-Rawashdeh, M., Yu, F., Nijhuis, T. A., Hessel, V., Schouten, J. C., \& Rebrov, E. V. (2012). Numbered-up gasliquid micro/milli channels reactor with modular flow distributor. Chemical Engineering Journal, 207-208, 645655. https://doi.org/10.1016/j.cej.2012.07.028

\section{Published in:}

Chemical Engineering Journal

\section{Document Version:}

Peer reviewed version

Queen's University Belfast - Research Portal:

Link to publication record in Queen's University Belfast Research Portal

\section{Publisher rights}

This is the author's version of a work that was accepted for publication in Open Chemical Engineering Journal. Changes resulting from the publishing process, such as peer review, editing, corrections, structural formatting, and other quality control mechanisms may not be reflected in this document. Changes may have been made to this work since it was submitted for publication. A definitive version was subsequently published in Open Chemical Engineering Journal, VOL 207-208, 10/2012

\section{General rights}

Copyright for the publications made accessible via the Queen's University Belfast Research Portal is retained by the author(s) and / or other copyright owners and it is a condition of accessing these publications that users recognise and abide by the legal requirements associated with these rights.

Take down policy

The Research Portal is Queen's institutional repository that provides access to Queen's research output. Every effort has been made to ensure that content in the Research Portal does not infringe any person's rights, or applicable UK laws. If you discover content in the Research Portal that you believe breaches copyright or violates any law, please contact openaccess@qub.ac.uk. 


\section{Accepted Manuscript}

Numbered-up Gas-liquid Micro/milli Channels Reactor With Modular Flow Distributor

M. Al-Rawashdeh, F. Yu, T.A. Nijhuis, E.V. Rebrov, V. Hessel, J.C. Schouten

PII:

S1385-8947(12)00919-9

DOI:

http://dx.doi.org/10.1016/j.cej.2012.07.028

Reference:

CEJ 9543

To appear in:

Chemical Engineering Journal

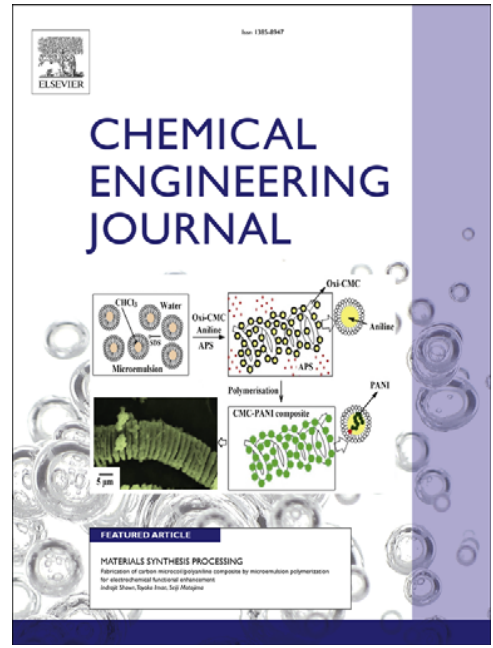

Received Date: $\quad 22$ March 2012

Revised Date: $\quad 2$ July 2012

Accepted Date: $\quad 3$ July 2012

Please cite this article as: M. Al-Rawashdeh, F. Yu, T.A. Nijhuis, E.V. Rebrov, V. Hessel, J.C. Schouten, Numberedup Gas-liquid Micro/milli Channels Reactor With Modular Flow Distributor, Chemical Engineering Journal(2012), doi: http://dx.doi.org/10.1016/j.cej.2012.07.028

This is a PDF file of an unedited manuscript that has been accepted for publication. As a service to our customers we are providing this early version of the manuscript. The manuscript will undergo copyediting, typesetting, and review of the resulting proof before it is published in its final form. Please note that during the production process errors may be discovered which could affect the content, and all legal disclaimers that apply to the journal pertain. 


\title{
Numbered-up Gas-liquid Micro/milli Channels Reactor With Modular Flow Distributor
}

\author{
M. Al-Rawashdeh ${ }^{\mathrm{a}}$, F. Yu ${ }^{\mathrm{a}}$, T.A. Nijhuis ${ }^{\mathrm{a}}$, E.V. Rebrov $^{\mathrm{b}}, \mathrm{V}$ Hessel $^{\mathrm{a}}$, \\ J.C. Schouten ${ }^{\mathrm{a}, *}$ \\ ${ }^{a}$ Laboratory of Chemical Reactor Engineering. Department of Chemical Engineering and \\ Chemistry. Eindhoven University of Technology. P.O. Box 513, 5600 MB Eindhoven, \\ The Netherlands. \\ ${ }^{b}$ Reactor and Process Engineering. School of Chemistry and Chemical Engineering. \\ Queen's University Belfast. BT9 5AG Belfast, United Kingdom.
}

\section{Abstract}

Gas-liquid processing in microreactors remains mostly restricted to the laboratory scale due to the complexity and expenditure needed for an adequate numbering-up with a uniform flow distribution. Here, the numbering-up is presented for multiphase (gas-liquid) flow in microreactor suitable for a production capacity of $\mathrm{kg} / \mathrm{h}$. Based on the barrier channels concept, the barrier-based micro/milli reactor (BMMR) is designed and fabricated to deliver flow non-uniformity of less than 10\%. The BMMR consists of eight parallel channels all operated in the Taylor flow regime and with a liquid flow rate up to $150 \mathrm{~mL} / \mathrm{min}$. The quality of the flow distribution is reported by studying two aspects. The first aspect is the influence of different viscosities, surface tensions and flow rates. The second aspect is the influence of modularity by testing three different reaction channels type: (1) square channels fabricated in a stainless steel plate, (2) square channels fabricated

*Corresponding author: Tel: +31 402472850 ; fax: +31 402446653.

Email address: J.C.Schouten@tue.nl ( J.C. Schouten) 
in a glass plate, and (3) circular channels (capillaries) made of stainless steel. Additionally, the BMMR is compared to that of a single channel regard the slug and bubble lengths and bubble generation frequency. The results pave the ground for bringing multiphase flow in microreactor one step closer for large scale production via numbering-up.

Keywords: Microreactor, Multiphase flow, Taylor flow, Design methodology, Scale-up

\section{Introduction}

The high rates of mass and heat transfer, minimum axial dispersion and the high interfacial area allow micro/milli channel reactors to run highly exothermic, toxic or even explosive reactions safely, permitting greener routes for processing $[1,2,3,4,5]$. Microreactors are very attractive devices for many different applications $[6,7,8,9]$. Different from the traditional scaleup, micro/milli channel reactors reach bulk chemicals productions via so called numbering up, placing multiple channels in parallel $[10,11,12,13]$. Because the dimensions of the microchannel where mixing, heating and reaction remains the same as those of the laboratory scale, industrial production starts directly from the lab. [14, 15, 16]

The simplest scheme for scale-up via numbering-up is shown in Figure 1. In the laboratory, scale-up of a single channel is investigated while "smartly" keeping the excellent properties of the micro/milli channels reactor $[17,10]$. The second scale-up step is to number-up the single channel in one single device - the modular unit. The last step is to arrange all these modular units together in what Hasebe [12] named the plant lay-out. 

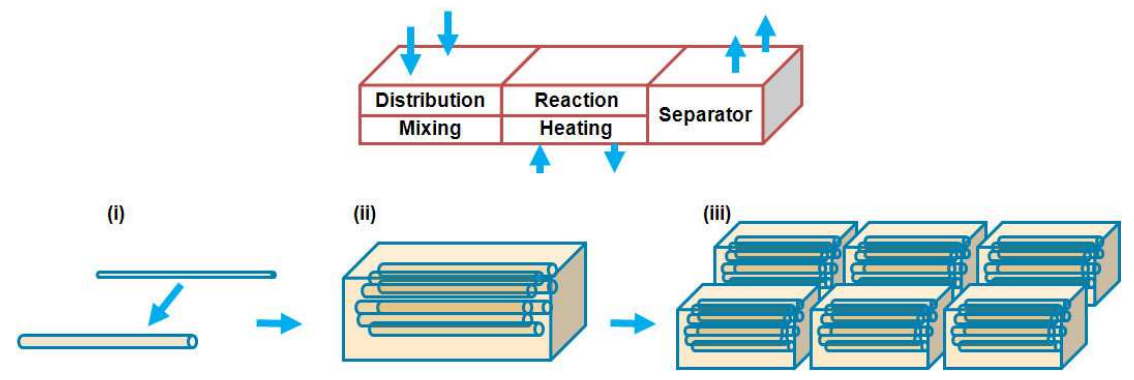

Figure 1: Scheme for the route of scale-up via numbering-up for micro/milli channel reactors. (i) scale-up of a single channel, (ii) modular unit, (iii) Multi-modular units.

The main block for the numbering-up is the modular unit. The modular unit can be defined as a device which contains different functional elements such as: distributor, mixer, reaction channels, heat exchanger and separator, and being fed by one single feeding unit for each phase. The modular unit should maintain equal flow conditions in the parallel channels, all of the functional elements should be integrated in one device, and the fabrication method should be suitable for bulk production of the reactor.

For single phase flow, many modular units are already available in the market for industrial production $[18,19,10,17]$. For multi-phase flow, development of modular units is still in a preliminary stage [20,21, 22]. This is mainly due to the difficulty in managing the flow distribution for multi-phase flow [23, 24, 20, 25]. Improper flow distribution, specially for gas-liquid flow, can result in a deformation of the flow pattern or in gas-liquid channeling [26, 27], some channels filled only with liquid while others are filled with gas.

The flow distribution depends on the hydraulic resistance in each of the parallel channels [28, 29, 30, 18]. In single phase flow, the hydraulic resistance depends on the physical properties of the fluids and on the hydraulic diameter 
of the channel. For multi-phase flow, the flow distribution depends on the properties of the single phase [31] and in addition on the flow rates, the specific gas-liquid interfacial area, the flow regime [32], and on the way the phases are in contact. The contact between the phases can be continuous like in the falling film microreactor [33] or dispersed like in segmented Taylor flow [34]. Here we only focus on gas-liquid flow in channels operated under the Taylor flow regime[35, 36]. Taylor flow is attractive due to its well-defined gas-liquid interface, reduced axial dispersion almost approaching plug flow, and high mass and heat transfer [35, 37].

Distributing gas and liquid flows to achieve Taylor flow regime in parallel channels can be achieved via branching, internal distribution (like in the monolith using a douche type), or by using separate gas and liquid feeding for each parallel channel [38]. When hydraulic resistances, so called barrier channels, are placed between the single phase flow distributor and the separate gas and liquid feeding for the parallel micro channels as shown in Figure 2, (1) gas-liquid channeling is prevented, (2) all flow regimes, viz. Taylor, churn and annular can be successfully realized, and (3) the flow uniformity is substantially improved $[20,25]$.

The barrier-based distributor is an excellent gas-liquid distributor for parallel channels operated in the Taylor flow regime. A major characteristic for this distributor is the hydraulic resistance needed to achieve equal flow distribution. This parameter can be quantified in a generic way as $\Delta \tilde{P}_{B}$ as given in Equation 1. It is the average pressure drop over the barrier channels $\overline{\Delta P_{B}}$ divided by the average pressure drop over the corresponding mixers and micro channels $\overline{\Delta P_{C}}$. Since $\Delta \tilde{P}_{B}$ is a ratio of pressure drops, it 
is dimensionless.

$$
\Delta \tilde{P}_{B}=\frac{\overline{\Delta P_{B}}}{\overline{\Delta P_{C}}}
$$

De Mas et al. [20] were among the first to demonstrate this type of distributor in micro channel reactors. Their design was successfully run but with barrier channels designed in the range of $\Delta \tilde{P}_{B}$ larger than 25 and 50 for liquid and gas, respectively. Al-Rawashdeh et al. [39] demonstrated that $\Delta \tilde{P}_{B}$ can be designed in the range of 4 to 25 by following a specific design methodology. The design methodology determines the maximum acceptable fabrication tolerance in the barrier channels, mixers and reaction channels.

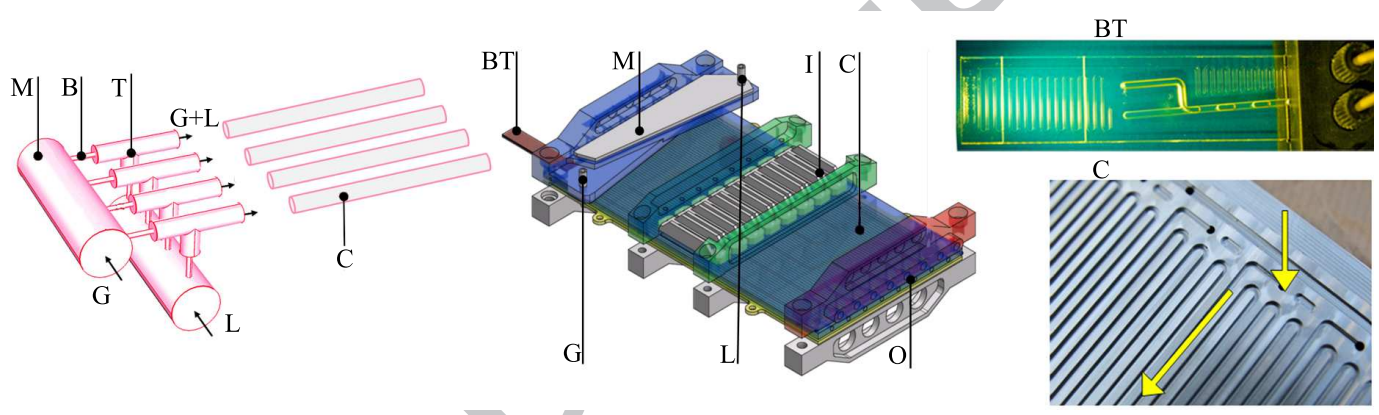

Figure 2: Left, schematic of barrier-based gas-liquid flow distributor for four parallel microchannels. Center, drawing of the $B M M R$ showing its components. Right, the barrier-mixer chip and the meandering of the reaction channels. Symbols used are: $(\mathrm{G})$ gas inlet, (L) liquid inlet, (M) manifold, (B) barrier channels, (T) T-mixer, (C) reaction channels,(BT) barrier-mixer chip, (I) inspection window, (O) collector block.

In this work, the barrier-based micro/milli reactor (BMMR) shown in Figure 2 was designed and fabricated according to the specific design methodology. The BMMR consists of eight parallel reaction channels all operated in the Taylor flow regime. It is designed to hold pressure up to 20 bar and 
temperature up to $200{ }^{\circ} \mathrm{C}$, however these two parameters are not examined in this paper. The BMMR is a modular type of reactor with a maximum liquid throughput of $150 \mathrm{~mL} / \mathrm{min}$ and gas to liquid flow ratio up to 10 .

The BMMR demonstrates the numbering-up concept for gas-liquid Taylor flow possible for a production capacity reaching $\mathrm{kg} / \mathrm{h}$. In this paper the quality of the flow distribution in the BMMR is reported by studying two aspects. The first aspect is to experimentally examine six different fluids with different viscosities, surface tensions and flow rates. The second aspect is to study the reactor modularity by testing three different reaction channels type: (1) square channels fabricated in a stainless steel plate, (2) square channels fabricated in a glass plate, and (3) circular channels (capillaries) made of stainless steel. Finally, the BMMR is compared to that of a single channel regard the slug and bubble lengths and bubble generation frequency. This paper present the quality of flow distribution in the BMMR which is an elementary step before operating a reaction which is the next aim. In the next section the design methodology and fabrication are presented. This is followed by a description of the experimental parts and operating conditions; then the results, and finally the discussion and conclusions.

\subsection{Design and fabrication}

The barrier-based micro/milli reactor was designed according to the design methodology as presented by Al-Rawashdeh et al.[39]. The design is made to deliver flow non-uniformity in the parallel channels of less than 10\%. The main functional elements of the reactor are shown in Figure 2:

The manifold $(M)$ : It is a triangular consecutive manifold made from stainless steel. Both the gas and liquid manifold dimensions are equal as 
given in Table 1. The volume of each manifold is half that of the reaction channels. The flow passes from the inlet, to the manifold volume and then split and delivered to the barrier-channels through a transport channels which were drilled in the manifold with an inner diameter of $2 \mathrm{~mm}$.

The barrier-mixer chip (BT): This chip is made from glass and it contains the barrier-channels and T-mixer as shown in Figure 2. The gas and liquid from the manifolds are delivered to the inlet of the barrier-channels. Taylor flow is generated in the T-mixer which then goes to the reaction channels through a transport channel. The glass chip is connected to the manifold and the reactor using O-rings. Dimensions of the mixer and barrier channels are given in Table 1. Fully developed laminar flow is maintained before the fluid reaches the mixers. The mixer and barrier channels were fabricated using powder blasting and chemical wet etching (Micronit), respectively. The fabrication tolerance of the barrier channels were measured using nano optical profiler (Bruker) giving an accuracy in the depth as shown in Figure 3.

The reaction channels $(C)$ : The generated Taylor flow passes to each of the eight reaction channels separately. Three types of reaction channels are fabricated as shown in Figure 4. The design of the reaction channels are arbitrarily made to cover different varieties of reaction channels design. However, the channel diameters and lengths were adjusted, as given in Table 1 , to deliver similar pressure drops in all of them. Pressure drop in the reaction channels is the key parameter to design the flow distributor.

The first channel type is square channels milled in a stainless steel plate and then closed by a metal sheet using brazing. Channels were fabricated in a meandering way as shown in Figure 1 and in Figure 3. The quality of 

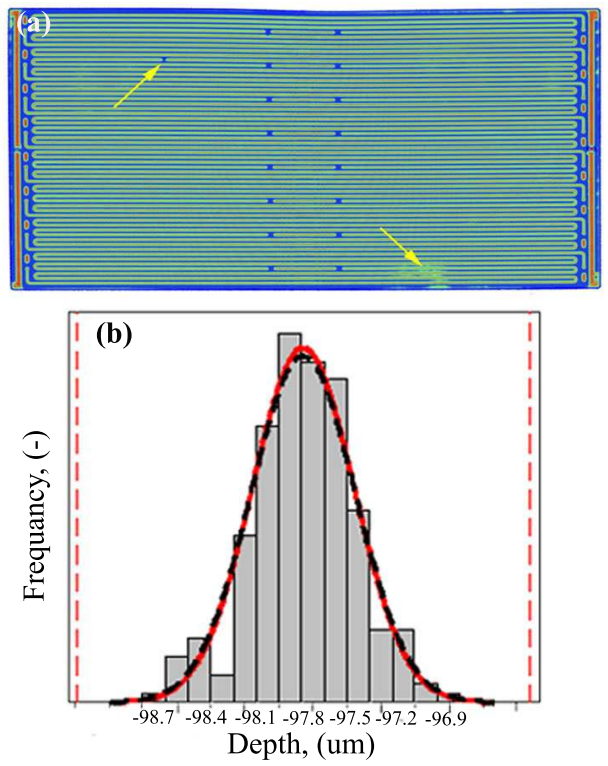

Figure 3: (a) Ultrasonic inspection for the brazing of the steel plate. (b) Histogram of the measured depth of the barrier channels at several positions in the BT chip shown in Figure 2 and for different chips.
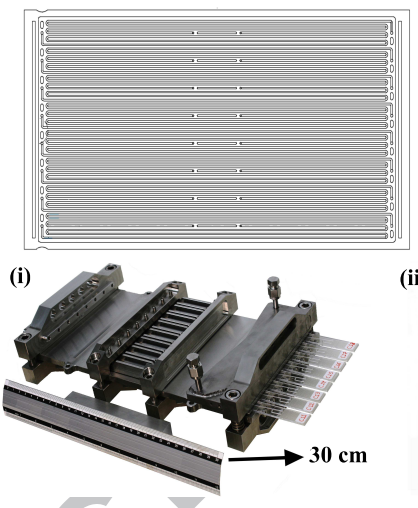

(ii)
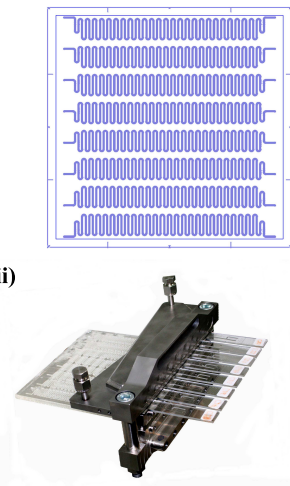

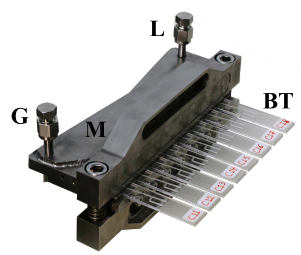

(iii)

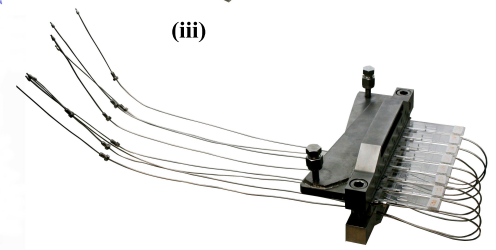

Figure 4: Photographs of the BMMR. Top right is the fixed manifolds (M) and barriermixer chips (BT) which used to connect the three reaction channels type. (i) Stainless steel plate with a drawing for the meandering reaction channels; (ii) Glass plate with a drawing for the meandering reaction channels; and (iii) Stainless steel capillaries. 
Table 1: Dimensions and Reynolds number for the barrier-based micro/milli reactor at an average operating condition of $q_{L}=74 \mathrm{ml} / \mathrm{min}$ and $q_{G} / q_{L}=2$. Superficial velocity of gas and liquid in the reaction channels are 0.2 and $0.1 \mathrm{~m} / \mathrm{s}$, respectively. Symbols refer to those explained in Figure 2; Subscript G and L refer to the gas and liquid, $\mathrm{T}$ is for the inlet channels of the mixer. ${ }^{*}$ The width is decreasing by an 8 degree angle.

\begin{tabular}{llllllc}
\hline & $\mathrm{d},(\mathrm{mm})$ & $\mathrm{W},(\mathrm{mm})$ & $\mathrm{H},(\mathrm{mm})$ & $\mathrm{L},(\mathrm{mm})$ & $\mathrm{Re},(-)$ & $\Delta P$, bar \\
\hline $\mathrm{M}_{G}$ & 6.4 & $41^{*}$ & 5 & 155 & 3 & 0.001 \\
$\mathrm{M}_{L}$ & 6.4 & $41^{*}$ & 5 & 155 & 20 & 0.001 \\
$\mathrm{~B}_{G}$ & - & 0.4 & $0.1 \pm 0.001$ & 340 & 65 & 1 \\
$\mathrm{~B}_{L}$ & - & 1.0 & $0.1 \pm 0.001$ & 37 & 183 & 1 \\
$\mathrm{~T}_{G}$ & - & 1.3 & 1.3 & 13 & 13 & - \\
$\mathrm{T}_{L}$ & - & 1.3 & 1.3 & 10 & 78 & - \\
$\mathrm{C}_{\text {Plate }}$ & - & 1.23 & 1.23 & 2000 & 245 & 0.15 \\
$\mathrm{C}_{\text {Glass }}$ & - & 1.1 & 0.87 & 1500 & 307 & - \\
$\mathrm{C}_{\text {Capillary }}$ & 0.75 & - & - & 667 & 403 & - \\
\hline
\end{tabular}

the brazing was tested using ultrasonic inspection (a technique used to test welding) as shown in Figure 3. Excellent brazing is obtained. To visualize the slug and bubbles in the steel plate, an inspection window is made by directing the flow to the top of the plate for a distance of $40 \mathrm{~mm}$ and then re-directing it back into the reaction channels in the steel plate. To measure the pressure drop over the reaction channels individually, an extra opening is made at the inlet and outlet of the reaction channels as shown in Figure 5. The second reaction channels type are square channels fabricated, using powder blasting (Lionix), in a glass plate with the dimensions given in Table 1 and shown 
in Figure 4(ii). The third reaction channels tested are the circular stainless steel capillaries. The steel capillaries were commercially available (Valco).

\section{Experiments and operating conditions}

The experiments were performed over a range of flow rates, surface tensions and viscosities as given in Table 2. All chemicals were ordered from VWR International. The viscosity was measured using a falling piston viscometer. The surface tension was measured using a tensiometer.

Table 2: Density $\rho$, viscosity $\mu$ and surface tension $\gamma$ of all six liquids used in the experiments in weight percentage. Liquid flow rate changes from $5 \mathrm{~mL} / \mathrm{min}$ to $150 \mathrm{~mL} / \mathrm{min}$. Gas to liquid flow ratio changes from 0.5 to 5.

\begin{tabular}{lllll}
\hline Fluid & No & $\rho,\left(\mathrm{kg} / \mathrm{m}^{3}\right)$ & $\mu,(\mathrm{Pa.s})$ & $\gamma,\left(\mathrm{N}^{-1}\right)$ \\
\hline $100 \%$ Water & 1 & 998 & 1.0 & 72.0 \\
$95 \%$ Water+5\% Ethanol & 2 & 989 & 1.5 & 52.4 \\
$80 \%$ Water+20\% Ethanol & 3 & 969 & 2.5 & 38.5 \\
$100 \%$ Ethanol & 4 & 789 & 1.6 & 22.3 \\
$70 \%$ Water+30\% Glycerol & 5 & 1072 & 2.5 & 70.3 \\
$50 \%$ Water+50\% Glycerol & 6 & 1126 & 6.0 & 69.1 \\
\hline
\end{tabular}

A process flow diagram of the experimental setup is shown in Figure 5. Liquid is being pumped using a gear pump (NHK Mikrosysteme GmbH, MZR-7205) with a liquid mass flow controller (Bronkhorst). Nitrogen is fed from a gas bottle and controlled using a mass flow controller (Bronkhorst). The pressure is measured at the manifold using a pressure sensor (range 0-25 bar, Endress+Hauser,PMP131). The pressure drop over the reaction chan- 


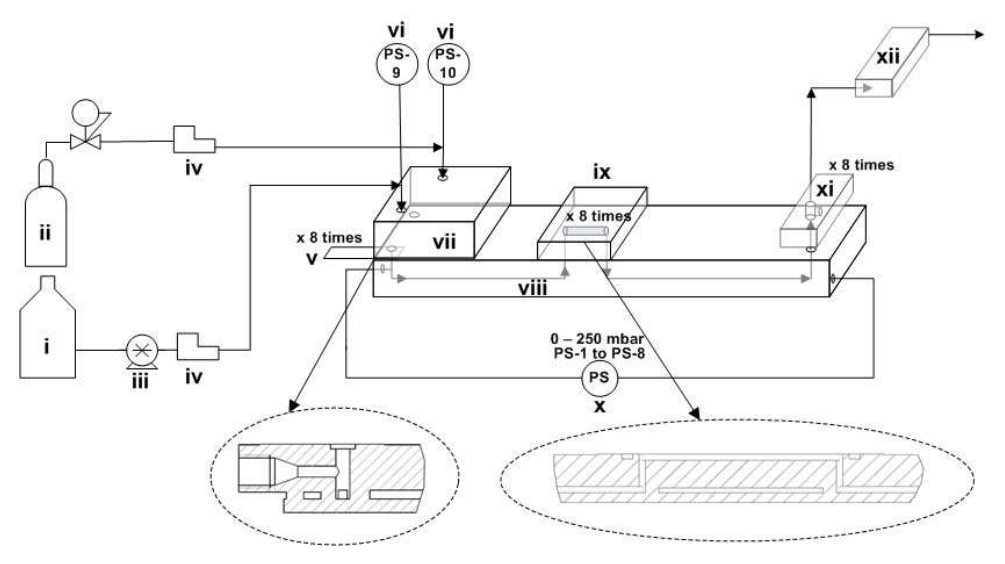

Figure 5: Process flow diagram of the experimental setup and the locations of the pressure sensors. Symbol used: (i) liquid tank, (ii) gas bottle, (iii) gear pump, (iv) mass flow controller, (v) BT glass chip, (vi) pressure sensors at the inlet, (vii) manifold, (viii) reaction channel plate, (ix) inspection window, (x) differantial pressure sensor, (xi) connection block, and (xii) collector block. The dotted circles are enlarged view of the connection and channel of a reaction channel in the steel plate.

nels is measured using a differential pressure sensor in the range of 0-250 mbar (Sensortechnics GmbH, 24PC). The bubble frequency in each barrier-mixer chip was measured using a portable stroboscope (Check.Line, DS-2000LED) which has a frequency range between 30 - 300,000 FPM. By synchronizing the bubble generation frequency with that of the stroboscope, it was possible to generate a static image of the slug and bubble of several unit cells of Taylor flow consisting of liquid slugs separated with gas bubbles. A handheld digital microscope (Dino-Lite, AD413TL) was used to record the image. By calibrating the image pixel with the width of the mixer channel, the slug and bubble lengths were measured in every channel with an accuracy of $\pm 50 \mu \mathrm{m}$. Slug length was measured as the length between two consecutive bubble caps as shown in the Figure 6. 
The measured bubble generation frequency and slug and bubble lengths allowed to calculate the bubble velocity per channel according to Equation 2. By quantifying the difference between the bubble velocities over the eight parallel channels, the flow non-uniformity was calculated using the relative standard deviation according to Equations 3 and 4.

$$
\begin{gathered}
u_{B}=f\left(L_{S}+L_{B}\right) \\
\sigma\left(u_{B}\right)=\frac{1}{\overline{u_{B}}} \sqrt{\frac{\sum_{i}\left(u_{B, i}-\overline{u_{B}}\right)^{2}}{N-1}} 100 \% \\
\overline{u_{B}}=\frac{\sum_{i=1}^{i=N} u_{B, i}}{N}
\end{gathered}
$$

The bubble velocity does not take into account the liquid film thickness as given in Equation 5 [40]. $A_{B}$ is cross section area of the bubble, $A$ is the channel cross section area, $U_{L}$ is the liquid superficial velocity, and $U_{G}$ is the gas superficial velocity. Equation 5 shows that part of the liquid flow in the channel (the one in the liquid film) is not taken into account when calculating the flow rate per channel. The amount of the liquid film in the channel depends on the capillary numbers and on the mode of operation for Taylor flow $[41,42]$. In the flow range investigated here, Taylor flow is operated in the recirculation mode and with a capillary number less than 0.04 . Therefore the liquid film occupy less than 0.17 of the channel cross section area [40]. Because bubble velocity is the most convenient way to measure flow rate per channel and because the liquid film will exist in all channels, the amount of the liquid film is not accounted for in the flow non-uniformity calculations. 


$$
u_{B}=\frac{A}{A_{B}}\left(U_{G}+U_{L}\right)
$$

\section{Results}

The BMMR is a modular reactor which integrates all of the functional elements (distributor, mixer, reaction channels, and heat exchanger) in a compatible and smooth way. The modularity of the BMMR using three reaction channels type is shown by the photographs in Figure 4. Exchanging the reaction channels while keeping the same manifolds and the barrier-mixer chips is relatively simple. The only fixed parameters in the BMMR are the outside dimensions of the manifolds and barrier-mixer chips and the location for the openings of the barrier-mixer chips. The inside dimensions and material of constructions of the reaction channels and the heat exchangers can be chosen freely. This is valid as long as the value of the pressure drop of the reaction channels matches the limits set by the design methodology [39]. If this is not the case, fabrication of a new set of barrier-mixer glass chips is needed which can be made according to the mentioned design methodology [39].

For demonstration, a typical experimental result obtained using the steel plate is shown in Figure 6 for an experiment using 100\% ethanol with nitrogen. At relatively low flow rates, the slugs and bubbles were captured in a single image at the inspection window. In all of the eight channels, slugs and bubbles were uniform and a stable Taylor flow was observed in the channels. By varying the gas and liquid flow rates as mentioned in Table 2, the residence time and specific interfacial area varied in the range of 1-120 (s) and 


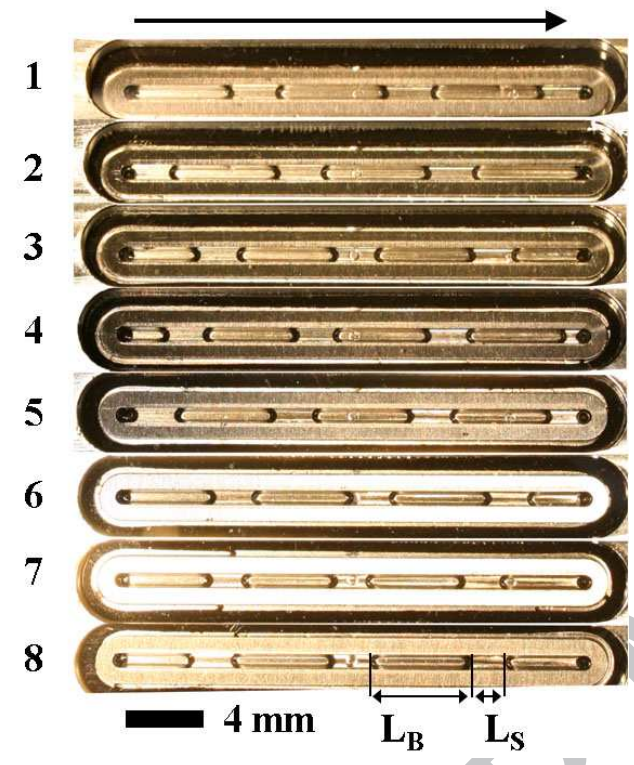

Figure 6: Typical result of the slug $\left(L_{S}\right)$ and bubble $\left(L_{B}\right)$ lengths distribution in the BMMR. Slug length is the length between two consecutive bubble caps as shown in the figure. Result shown is for $100 \%$ ethanol with nitrogen in the steel plate reaction channels with flow rates equal to $5 \mathrm{~mL} / \mathrm{min}$ and $10 \mathrm{~mL} / \mathrm{min}$ for liquid and gas, respectively. 
1000-5000 $\left(\mathrm{m}^{2} / \mathrm{m}^{3}\right)$, respectively.

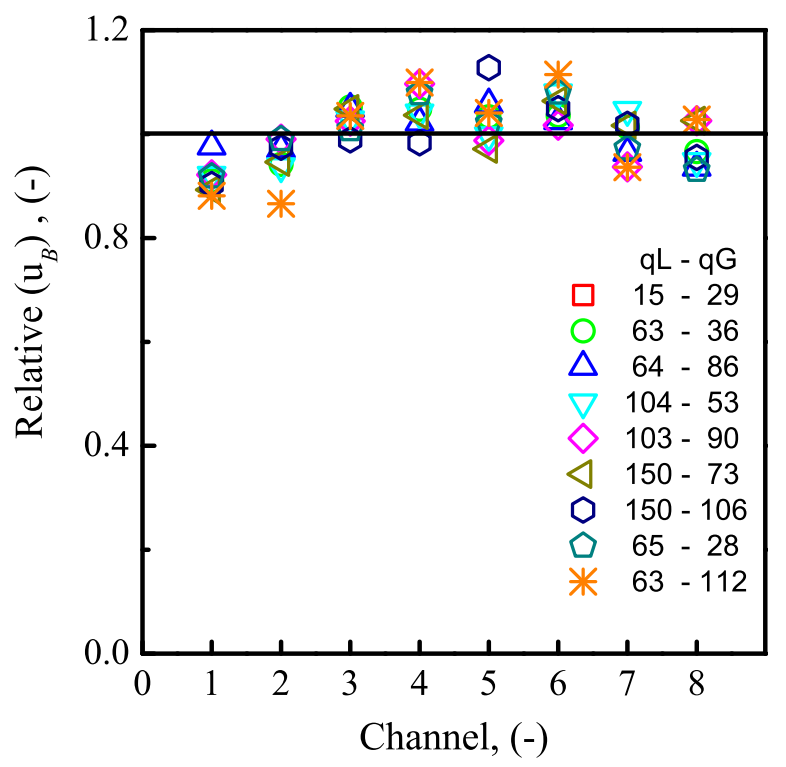

Figure 7: Relative bubble velocity (divided by average velocity) per channel for the case of ethanol-nitrogen over a wide rate of flow rates for gas ( $\mathrm{qG}, m L_{n} / m i n$ )and liquid ( $\mathrm{qL}$, $\mathrm{mL} / \mathrm{min})$.

The flow non-uniformity was quantified using the relative standard deviation given in Equation 3. To use that equation, the flow rate of each channel must be constant over time. Fluctuation of flow rate over time was observed in some cases when bubble or slug coalescence occur and when pump fluctuated specially at large flow rates. The degree of that fluctuation was quantified by measuring the range of bubble generating frequency where fluctuations observed using the stroboscope. Fluctuations in the frequency were in all cases less than $3 \%$. Because of that, fluctuation of flow rate of a channel over time was neglected and average bubble generating frequency was used instead. For a wide range of flow rates, the flow rate per channel 
is shown in Figure 7 to demonstrate the profile of the flow distribution. The relative bubble velocity per channel for the case of nitrogen-ethanol flow is plotted over the eight parallel channels. In center channels, flow rate is the largest and decreases elsewhere. Over the entire flow rate tested, profile of the flow distribution remains the same. However the broadness of that profile depended on the flow rate. Quantifying that broadness which is the flow non-uniformity at varied conditions will be discussed in further details in the next sections.

\subsection{Liquid versus gas-liquid flow distribution}

The first experiment to examine the flow non-uniformity is made by studying the influence of flow rate for each phase separately. This was done in two separate experiments both using ethanol-nitrogen flow in the steel plate. In the first, only liquid phase was measured by collecting the outlet of each reaction channel into a separate vessel, then measuring the collected weight over time. In the second experiment, experiment 1 was repeated but instead the gas and bubble velocity per channel was measured. The liquid flow non-uniformity is shown in Figure 8 (i), the non-uniformity in the bubble velocity shown in Figure 8 (ii) and the relative pressure difference shown in Figure 8 (iii). For the liquid phase only, the flow non-uniformity remains less than 3\%. For the bubble velocity, the non-uniformity is twice larger; it is between $5 \%$ and $10 \%$. This demonstrates that the gas flow non-uniformity

is twice larger than that of the liquid.

The only difference between the gas and liquid manifolds and barrier sections of the reactor is the width of the barrier channel. In the fabrication process, wet chemical etching is used simultaneously to fabricate the barrier 

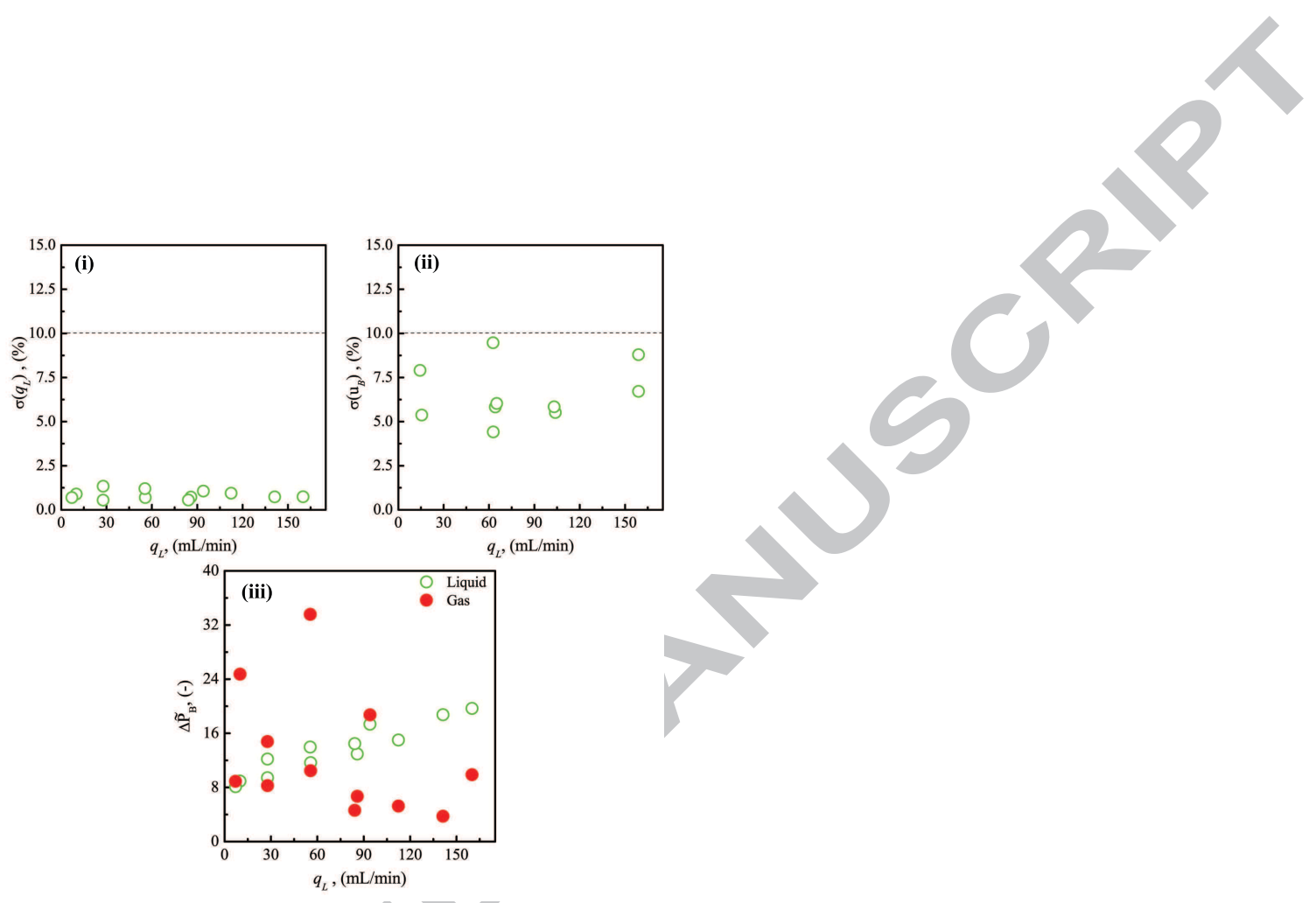

Figure 8: (i) Liquid flow non-uniformity $\sigma\left(q_{L}\right)$ and (ii) bubble velocity non-uniformity $\sigma\left(u_{B}\right)$ at varied gas and liquid (100\% ethanol) flow rates. (iii) Experimental result of $\Delta \tilde{P}_{B}$. 
channels of the gas and liquid channels. Therefore the absolute fabrication tolerance in the width for both channels is the same. But since the width of the gas barrier channel is 2.5 times less than that of the liquid barrier channel, the relative tolerance is larger. However one should keep in mind that for both experiments, the non-uniformity remains within the acceptable margin of $10 \%$. Moreover, in both experiments $\Delta \tilde{P}_{B}$ remains within the optimal range of 4 to 25 for the entire flow rate tested as shown in Figure 8 (iii).

\subsection{Stainless steel plate reactor - Effect of physical properties}

The influence of viscosities, surface tensions and flow rates on the flow non-uniformity in the stainless steel plate are shown in Figure 9. All of these parameters were included in one dimensionless number, the capillary number $C a_{B}=\frac{\mu \cdot u_{B}}{\gamma} . C a_{B}$ is used because it contains the viscosity, surface tension, bubble generation frequency, and slug and bubble lengths. For all of the six fluids and for the entire range of flow rates, the flow non-uniformity remains within the acceptable flow non-uniformity of $10 \%$, with two exceptions. The first is at large flow rate, when $C a_{B}$ approaches 0.04 . The non-uniformity for the $50 \%$ glycerol and $30 \%$ glycerol approaches the maximum limit of $10 \%$. This can be explained by the influence of manifold on the flow distribution. The flow non-uniformity in a consecutive type of manifold increases as the flow rate or the viscosity increases. [28, 43]

The second exception (where the flow non-uniformity exceeds the 10\%) is at low flow rate when $C a_{B}$ is less than $2.5 \times 10^{-3}$. This exception can be explained by the wettability and the liquid film thickness. Before explaining that, it is important to notice that at low flow rates (low $\left.C a_{B}\right), \Delta \tilde{P}_{B}$ is 


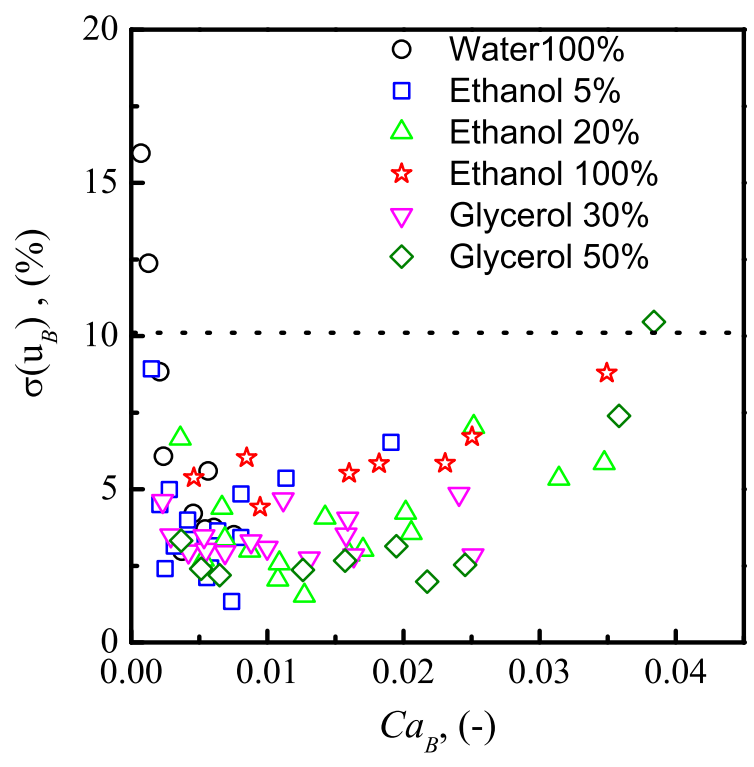

Figure 9: Bubble velocity non-uniformity for six fluids given in Table 2 versus capillary number $C a_{B}=\frac{\mu \cdot u_{B}}{\gamma} . C a$ is calculated as an average over the eight parallel channels.

the lowest. As $\Delta \tilde{P}_{B}$ decreases, the influence of variations in the reaction channels (flow rates, slug and bubble lengths, and fabrication tolerance) on the flow distribution increases. This relation was mathematically obtained by Al-Rawashdeh et al. [39] and given in Equation 6.

$$
\sigma\left(\tilde{q}_{C}\right)=\frac{\sigma\left(\Delta P_{C}\right)}{\Delta \tilde{P}_{B}}
$$

$\sigma\left(\Delta P_{C}\right)$ is the variation in pressure drops over the reaction channels, and $\sigma\left(\tilde{q}_{C}\right)$ is the flow non-uniformity due to the flow rates and all variations in the mixers and reaction channels. Keeping Equation 6 in mind, as the liquid flow rate or the viscosity decreases, the liquid film thickness decreases [44]. As the liquid film thickness decreases and because there are sharp bends in the transport channels and reaction channels (see Figure 5), it is possible that 
partially dry walls could form. The partially dry walls can induce bubble coalescence especially at lower slug lengths (when the length is similar or lower than the channel diameter [45]). Bubble coalescence generate pressure fluctuating over the reaction channels $\left(\sigma\left(\tilde{q}_{C}\right)\right.$ increase $)$ and produces larger flow non-uniformity.
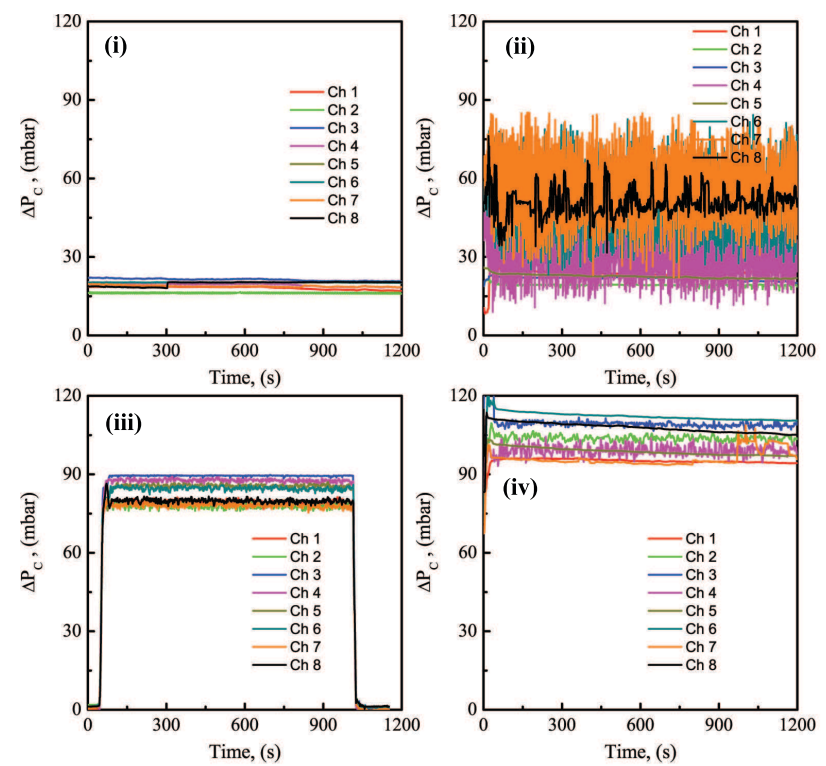

Figure 10: Steady state pressure drop of the eight reaction channels over time for $100 \%$ ethanol (i and iii) and $100 \%$ water (ii and iv). The operating conditions are $\mathrm{qL}=14$ $\mathrm{mL} / \min$ and $\mathrm{qG}=30 \mathrm{~mL} / \mathrm{min}$ for $\mathrm{i}$ and $\mathrm{ii}$, and $\mathrm{qL}=50 \mathrm{~mL} / \mathrm{min}$ and $\mathrm{qG}=130$ $m L_{n} / \min$ for iii and iv. Figure is printed in color.

Figure 10 shows the steady state pressure drop of the eight reaction channels over time for $100 \%$ water and $100 \%$ ethanol. At low flow rate, the pressure drop for the $100 \%$ ethanol is very smooth. Thus, uniform and stable Taylor flow is formed. Using 100\% water, large fluctuations in pressure drops are observed which indicates that Taylor flow is not stable and bubble coa- 
lescence occurs which was also visually observed. As the flow rates increases, a smooth steady state pressure drop is observed for both fluids. To maintain flow non-uniformity as low as possible, assuring a good wetting in the channel where Taylor flow passes is mandatory. This was obtained when $C a_{B}$ is between $2.5 \times 10^{-3}$ and $3.8 \times 10^{-2}$.

\subsection{Effect of reaction channel types and dimensions}

The influence of modularity and reaction channels type on the flow nonuniformity are shown in Figure 11 and Figure 12 using 100\% ethanol and $100 \%$ water, respectively. Using $100 \%$ ethanol, the flow non-uniformity remains within the acceptable range of less than 10\%. Using $100 \%$ water and at lower flow rate $\left(C a_{B}\right.$ less than 0.002$)$, the flow non-uniformity of the channels made of steel exceeds $10 \%$. However for the glass plate, the non-uniformity remains less than $10 \%$. The glass plate has smaller channel diameter and shows a better wettability compared to the steel plate. That could explains why the the flow non-uniformity remains less than $10 \%$ for the glass plate. The circular channels did not perform better than the square channels. Most probably this is due to the transport channels shown in Figure 5. Transport channels are the ones which transport Taylor flow from the barrier-mixer chip to the reaction channels through a connector block made of stainless steel. Transport channels are connected to the eight capillaries via capillary fittings. The connection contains bends and sharp edges. It is possible that the wetting in the transport channels is not good, which could result in bubble coalescence. If bubble coalescence occurs, the pressure drop over the reaction channels starts to fluctuate significantly as shown in Figure 10. At low flow rate, the value of $\Delta \tilde{P}_{B}$ is the smallest. Therefore, the interaction 
between the pressure fluctuations and the flow distribution is the largest [38]. Stable and uniform Taylor flow was observed in the three reaction channels type for almost the entire range examined here. This proofs that the choice to keep same pressure drop in the channels is the key for modularity to use same distributor for different reaction channels and dimensions. In addition result shows that reaction channel geometry and dimension has no significant influence on flow distribution if pressure drop is maintained similar to each other.

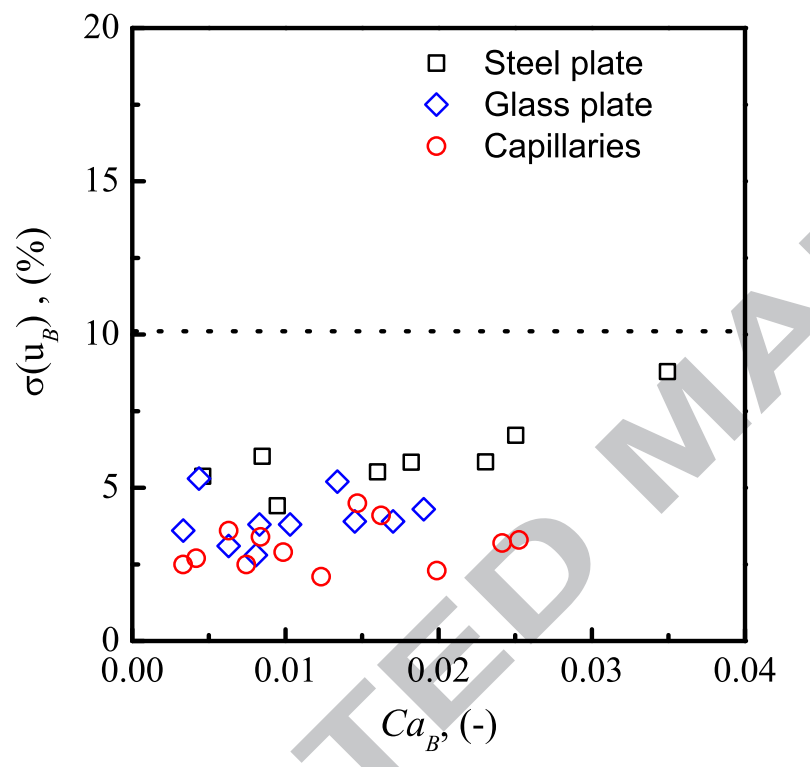

Figure 11: Bubble velocity non-uniformity using $100 \%$ ethanol for the 3 reaction channels given in Table 1 and shown in Figure 4 versus capillary number $C a_{B}=\frac{\mu \cdot u_{B}}{\gamma}$. 


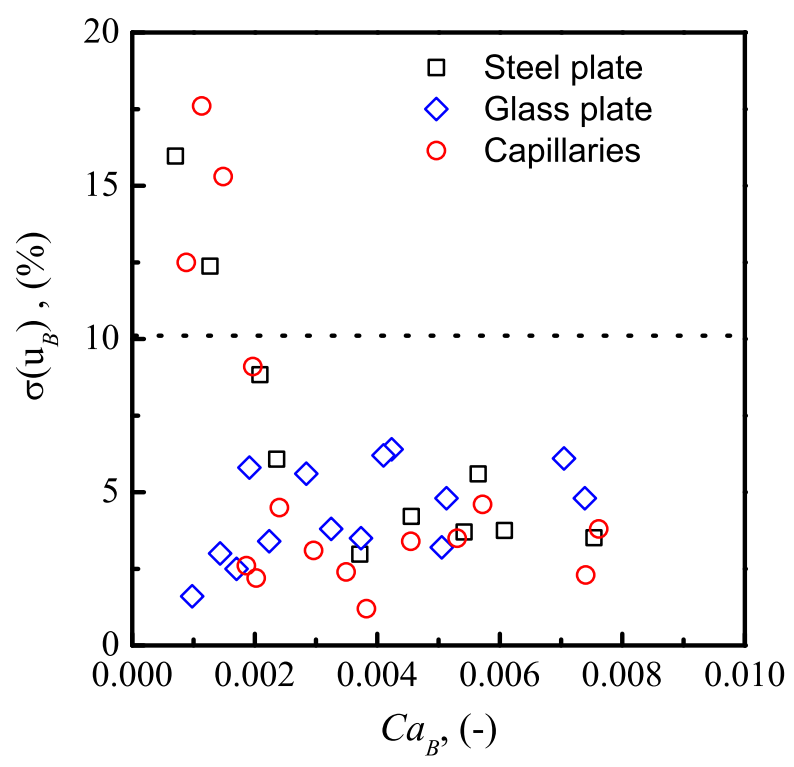

Figure 12: Bubble velocity non-uniformity $\sigma\left(u_{B}\right)$ using $100 \%$ water for the 3 reaction channels given in Table 1 and shown in Figure 4 versus capillary number $C a_{B}=\frac{\mu \cdot u_{B}}{\gamma}$.

\subsection{Comparison to single channel - Bubble generation frequency and slug and bubble lengths}

The BMMR is compared to that of a single channel regard the bubble generating frequency as a function of flow rates. In Figure 13, the bubble generation frequency $f$ is plotted versus the flow rate. The flow rate is represented by Reynolds number $R e_{B}$ to allow comparison to that from the single channel results [46]. Average values of $f$ and $R e_{B}$ are calculated over the eight parallel channels. The bubble generating frequency is a linear function of the Reynolds number. As the viscosity increases the slope increases in the same manner as that of Laborie et al. [46]. The BMMR result matches with that of the single channel [46]. Therefore, even with the non-uniformity in the flow rates and slug and bubble lengths, the BMMR reactor still shows 
similar performance to that of a single channel.

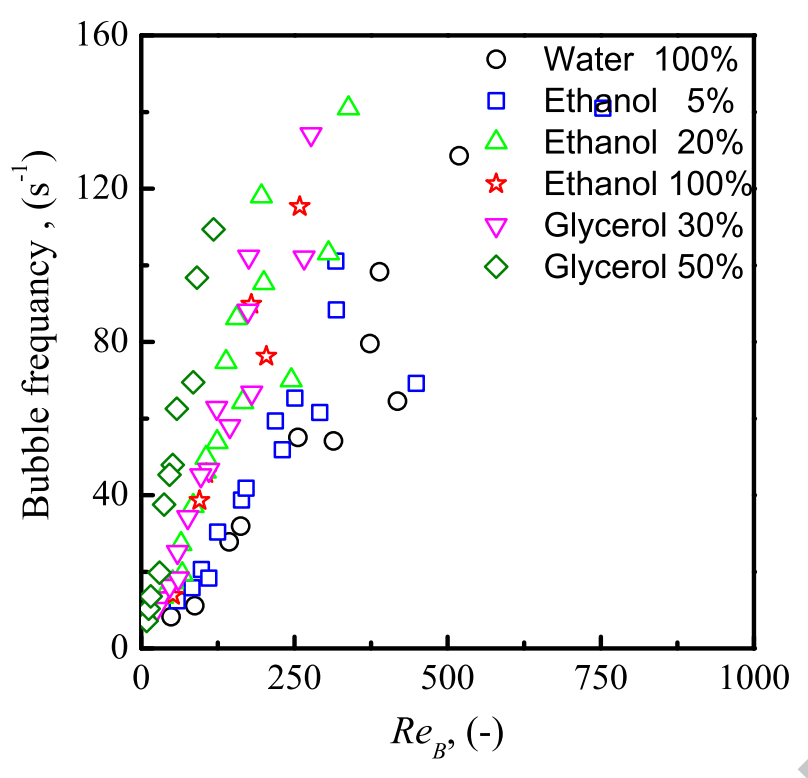

Figure 13: Bubble generating frequency as a function of Reynolds number $\left(R e=\frac{\rho_{L} d u_{B}}{\mu_{L}}\right)$ for the six fluids given in Table 2 .

In Figure 14, The BMMR is compared to that of a single channel regard the slug and bubble lengths as a function of the gas flow rates at a fixed liquid flow rate of $50 \mathrm{ml} / \mathrm{min}$. As the gas flow rate increases, the slug length decreases while the bubble length increases linearly. The non-uniformity in the bubble velocity is plotted as a function of gas flow rate. As the flow rate increases, the non-uniformity decreases reaching a kind of minimum. At high flow rate, the slug lengths are lower than that of the reaction channels. Oztaskin et al. [45] demonstrated that as the slug lengths is equal to or lower than the channel diameter, Taylor flow is not stable because the velocity profile in the liquid slug is not fully developed. The non-stable Taylor flow result in bubble coalescence. Thus fluctuation occurs in pressure drops in 
the reaction channels, which result in larger flow non-uniformities. As the viscosity and surface tension changed, there was no significant influence on the slug and bubble lengths. This is different than what was reported in literature [44] for studies made in a single channel. Most probably this is because of slug and bubble lengths non-uniformity over the eight parallel channels is comparable to those from changing viscosity and surface tension.
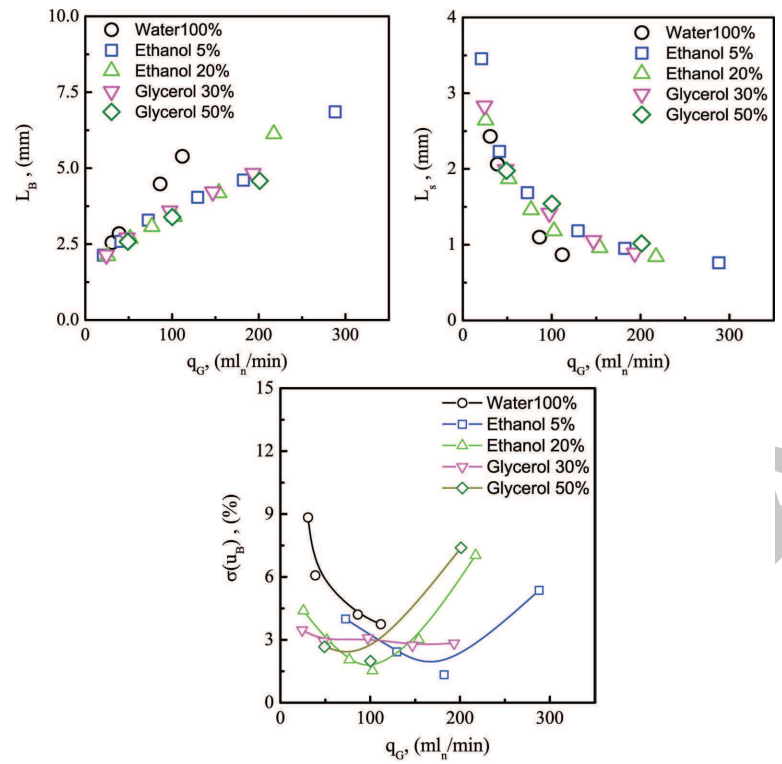

Figure 14: Upper, slug and bubble length as a function of gas flow rate at fixed liquid flow rate of $50 \mathrm{~mL} / \mathrm{min}$. Lower, Bubble velocity non-uniformity as a function of gas flow rate at fixed liquid flow rate.

\section{Conclusion}

The barrier-based micro/milli reactor has been successfully designed according to the methodology purposed by Al-Rawashdeh et al. [39] to provide a flow non-uniformities of less than 10\%. The flow non-uniformity is experi- 
mentally examined by studying two aspects. The first aspect is by changing the viscosities, surface tensions and the flow rates for six different fluids. The second aspect is by studying the reactor modularity using three reaction channels type: (1) square channels fabricated in stainless steel plate, (2) square channels fabricated in glass plate, and (3) circular channels (capillaries) made of stainless steel. Finally the BMMR is compared to that of a single channel regards the slug and bubble lengths and the bubble generating frequency. Conclusions obtained are:

1. The flow non-uniformity for the $B M M R$ remains less than the acceptable margin of $10 \%$ when: liquid flow rate changed from 10-150 $\mathrm{mL} / \mathrm{min}$, gas to liquid ratio of 0.5 - 5, viscosity of $1.25-6.71$ (Pa.s), and surface tensions of $0.028-0.083\left(\mathrm{~N} . \mathrm{m}^{-1}\right)$.

2. To maintain flow non-uniformity as low as possible and less than the $10 \%$, assuring a good wetting in the channel where Taylor flow passes is mandatory. This was obtained when $C a_{B}$ is between $2.5 \times 10^{-3}$ and $3.8 \times 10^{-2}$.

3. To prevent pressure fluctuations and reduce the flow non-uniformities, slug and bubble lengths should be larger than 2 times the channel diameters.

4. Reaction channel geometry and dimension have no significant influence on flow distribution as far as the pressure drop maintain the same. The key parameter for modularity over varied channel dimensions and geometries is the pressure drop. To exchange various reaction channels using the same distributor (same barrier-mixer chips), similar value for the pressure drop is required. 
In summary, this paper presented the BMMR which demonstrate the numbering-up of gas-liquid Taylor flow in microreactor suitable for a production capacity of $\mathrm{kg} / \mathrm{h}$. A uniform flow distribution is achieved at varied conditions even at larger viscosity which can be attractive for certain applications like sulfonation or polymerization reactions. The study of the flow distribution is an elementary step made before performing a reaction in the BMMR which will be the next target.

\section{Acknowledgement}

The authors gratefully acknowledge the financial support by the Dutch Technology Foundation (STW) project number (07979) with the support from the Industrial Advisory Board (IROP) of the Netherlands Research School in Process Technology (OSTP) and Micronit.

\section{References}

[1] C. Wiles, P. Watts, Continuous flow reactors: a perspective, Green Chemistry 14 (2012) 38-54.

[2] R. L. Hartman, K. F. Jensen, Microchemical systems for continuous-flow synthesis., Lab on a Chip 9 (2009) 2495-2507.

[3] T. Razzaq, T. N. Glasnov, C. O. Kappe, Accessing novel process windows in a high-temperature/pressure capillary flow reactor, Chem. Eng. Technol. 32 (2009) 1702-1716.

[4] N. Kockmann, D. M. Roberge, Harsh reaction conditions in continuous- 
flow microreactors for pharmaceutical production, Chemical Engineering \& Technology 32 (2009) 1682-1694.

[5] V. Hessel, Novel process windows - gate to maximizing process intensification via flow chemistry, Chemical Engineering \& Technology 32 (2009) 1655-1681.

[6] D. M. Roberge, L. Ducry, N. Bieler, P. Cretton, B. Zimmermann, Microreactor technology: A revolution for the fine chemical and pharmaceutical industries?, Chemical Engineering \& Technology 28 (2005) 318323.

[7] H. Pennemann, P. Watts, S. Haswell, V. Hessel, H. Lowe, Benchmarking of microreactor applications, Organic Process Research \& Development 8 (2004) 422-439.

[8] B. P. Mason, K. E. Price, J. L. Steinbacher, A. R. Bogdan, D. T. McQuade, Greener approaches to organic synthesis using microreactor technology, Chemical Reviews 107 (2007) 2300-2318.

[9] A. Gunther, K. F. Jensen, Multiphase microfluidics: from flow characteristics to chemical and materials synthesis., Lab on a Chip 6 (2006) $1487-1503$.

[10] A. Tonkovich, D. Kuhlmann, A. Rogers, J. McDaniel, S. Fitzgerald, R. Arora, T. Yuschak, Microchannel technology scale-up to commercial capacity, Chemical Engineering Research and Design 83 (2005) 634-639. 
[11] A. Gavriilidis, P. Angeli, E. Cao, K. Yeong, Y. Wan, Technology and applications of microengineered reactors, Chemical Engineering Research and Design 80 (2002) 3-30.

[12] S. Hasebe, Design and operation of micro-chemical plants-bridging the gap between nano, micro and macro technologies, Computers \& Chemical Engineering 29 (2004) 57-64.

[13] R. Natividad, J. Cruz-Olivares, R. Fishwick, J. Wood, J. Winterbottom, Scaling-out selective hydrogenation reactions: From single capillary reactor to monolith, Fuel 86 (2007) $1304-1312$.

[14] J. C. Charpentier, In the frame of globalization and sustainability, process intensification, a path to the future of chemical and process engineering (molecules into money), Chemical Engineering Journal 134 (2007) 84-92.

[15] D. Kralisch, G. Kreisel, Assessment of the ecological potential of microreaction technology, Chemical Engineering Science 62 (2007) 10941100.

[16] T. Bayer, J. Jenck, M. Matlosz, Impulse - a new approach to process design, Chemical Engineering \& Technology 28 (2005) 431-438.

[17] N. Kockmann, M. Gottsponer, D. M. Roberge, Scale-up concept of single-channel microreactors from process development to industrial production, Chemical Engineering Journal 167 (2011) 718 - 726.

[18] E. V. Rebrov, J. C. Schouten, M. H. de Croon, Single-phase fluid flow 
distribution and heat transfer in microstructured reactors, Chemical Engineering Science 66 (2010) 1374-1393.

[19] Z. Anxionnaz, M. Cabassud, C. Gourdon, P. Tochon, Heat exchanger/reactors (hex reactors): Concepts, technologies: State-of-theart, Chemical Engineering and Processing: Process Intensification 47 (2008) 2029-2050.

[20] N. De Mas, A. Gunther, T. Kraus, M. Schmidt, K. Jensen, Scaled-out multilayer gas-liquid microreactor with integrated velocimetry sensors, Industrial \& Engineering Chemistry Research 44 (2005) 8997-9013.

[21] S. Marre, A. Adamo, S. Basak, C. Aymonier, K. F. Jensen, Design and packaging of microreactors for high pressure and high temperature applications, Industrial \& Engineering Chemistry Research 49 (2010) $11310-11320$.

[22] V. Hessel, C. Knobloch, H. Lwe, Review on patents in microreactor and micro process engineering, Recent Patents on Chemical Engineering 1 (2008) 1-16.

[23] M. Mendorf, H. Nachtrodt, A. Mescher, A. Ghaini, D. W. Agar, Design and control techniques for the numbering-up of capillary microreactors with uniform multiphase flow distribution, Industrial \& Engineering Chemistry Research 49 (2010) 10908-10916.

[24] M. Kashid, A. Gupta, A. Renken, L. Kiwi-Minsker, Numbering-up and mass transfer studies of liquid-liquid two-phase microstructured reactors, Chemical Engineering Journal 158 (2010) 233 - 240. 
[25] Y. Wada, M. Schmidt, K. Jensen, Flow distribution and ozonolysis in gas-liquid multichannel microreactors, Industrial \& Engineering Chemistry Research 45 (2006) 8036-8042.

[26] V. Haverkamp, V. Hessel, H. Lowe, G. Menges, M. Warnier, E. Rebrov, M. De Croon, J. Schouten, M. Liauw, Hydrodynamics and mixerinduced bubble formation in micro bubble columns with single and multiple-channels, Chemical Engineering \& Technology 29 (2006) 10151026.

[27] J. Yue, R. Boichot, L. Luo, Y. Gonthier, G. Chen, Q. Yuan, Flow distribution and mass transfer in a parallel microchannel contactor integrated with constructal distributors, AIChE Journal 56 (2010) 298-317.

[28] M. Pan, Y. Tang, H. Yu, H. Chen, Modeling of velocity distribution among microchannels with triangle manifolds, AIChE Journal 55 (2009) 1969-1982.

[29] C. Amador, A. Gayriilidis, P. Angeli, Flow distribution in different microreactor scale-out geometries and the effect of manufacturing tolerances and channel blockage, Chemical Engineering Journal 101 (2004) 379-390.

[30] J. M. Commenge, L. Falk, J. P. Corriou, M. Matlosz, Optimal design for flow uniformity in microchannel reactors, AIChE Journal 48 (2002) 345-358.

[31] M. Warnier, M. de Croon, E. Rebrov, J. Schouten, Pressure drop of 
gas-liquid taylor flow in round micro-capillaries for low to intermediate reynolds numbers, Microfluidics and Nanofluidics 8 (2010) 33-45.

[32] N. Shao, A. Gavriilidis, P. Angeli, Flow regimes for adiabatic gas-liquid flow in microchannels, Chemical Engineering Science 64 (2009) 2749 2761.

[33] R. D. Chambers, M. A. Fox, D. Holling, T. Nakano, T. Okazoe, G. Sandford, Elemental fluorinepart 16. versatile thin-film gas-liquid multichannel microreactors for effective scale-out., Lab on a Chip 5 (2005) 191-198.

[34] V. Hessel, P. Angeli, A. Gavriilidis, H. Lowe, Gas-liquid and gas-liquidsolid microstructured reactors: Contacting principles and applications, Industrial \& Engineering Chemistry Research 44 (2005) 9750-9769.

[35] P. Angeli, A. Gavriilidis, Hydrodynamics of taylor flow in small channels: a review, Proceedings of the Institution of Mechanical Engineers, Part C: Journal of Mechanical Engineering Science 222 (2008) 737-751.

[36] H. Song, D. L. Chen, R. F. Ismagilov, Reactions in droplets in microfluidic channels, Angewandte Chemie International Edition 45 (2006) $7336-7356$.

[37] R. Gupta, D. Fletcher, B. Haynes, Taylor flow in microchannels: A review of experimental and computational work, The Journal of Computational Multiphase Flows 2 (2010) 1-32.

[38] M. Al-Rawashdeh, L. Fluitsma, T. Nijhuis, E. Rebrov, V. Hessel, 
J. Schouten, Design criteria for a barrier-based gas-liquid flow distributor for parallel microchannels, Chemical Engineering Journal 181-182 (2012) 549-556.

[39] M. Al-Rawashdeh, T. Nijhuis, E. Rebrov, V. Hessel, J. Schouten, Design methodology for barrier-based two phase flow distributor, AIChE J. (2012) Accepted.

[40] M. Warnier, E. Rebrov, M. de Croon, V. Hessel, J. Schouten, Gas holdup and liquid film thickness in taylor flow in rectangular microchannels, Chemical Engineering Journal 135 (2008) S153 - S158.

[41] G. I. Taylor, Deposition of a viscous fluid on the wall of a tube, Journal of Fluid Mechanics 10 (1961) 161-165.

[42] R. Abiev, Circulation and bypass modes of the slug flow of a gasliquid mixture in capillaries, Theoretical Foundations of Chemical Engineering 43 (2009) 298-306.

[43] G. Griffini, A. Gavriilidis, Effect of microchannel plate design on fluid flow uniformity at low flow rates, Chemical Engineering \& Technology 30 (2007) 395-406.

[44] D. M. Fries, F. Trachsel, P. R. von Rohr, Segmented gas-liquid flow characterization in rectangular microchannels, International Journal of Multiphase Flow 34 (2008) 1108 - 1118.

[45] M. C. Oztaskin, M. Worner, H. S. Soyhan, Numerical investigation of the stability of bubble train flow in a square minichannel, Physics of Fluids 21 (2009) 042108. 
[46] S. Laborie, C. Cabassud, L. Durand-Bourlier, J. Laine, Characterisation of gas-liquid two-phase flow inside capillaries, Chemical Engineering Science 54 (1999) 5723-5735. 
- Numbering-up gas-liquid flow in microreactor suitable for $\mathrm{kg} / \mathrm{h}$ production capacity

- Flow non-uniformity is studied using barrier-channels concept

- Taylor flow with uniformity larger than $90 \%$ existed in all 8 parallel channels

- Six fluids are studied with different viscosities, surface tensions and flow rates

- Three channels type are studied square and circular in steel and square in glass 